\title{
ESTIMATION OF PASSENGER CAR UNITS FOR HETEROGENEOUS TRAFFIC CONDITION USING VEHICULAR SPEED AND COMPOSITION AT MID - BLOCK SECTION
}

\author{
Burma Vamshi Krishna ${ }^{1}$, Adepu Ramesh' ${ }^{2}$, Molugaram Kumar ${ }^{3}$ \\ 1,2 Department of Civil Engineering, VNR Vignana Jyothi Institute of Engineering and Technology, \\ Hyderabad, Telangana, India \\ ${ }^{3}$ Department of Civil Engineering, University College of Engineering, Osmania University, Hyderabad, \\ Telangana, India
}

Received 1 July 2019; accepted 28 September 2019

\begin{abstract}
Traffic conditions in India are entirely different from other developed countries of the world. The traffic flow is highly dynamic in nature and observed at all mid - block section and interaction of vehicles is also expected to change with the mix characteristics. It is also observed that the interaction among the vehicles is maximum and highly complex during peak period. In this situation the mixed traffic condition situation different types of vehicles share the same roadway space without any physical segregation. The interaction of vehicles under above situation is expressed as the amount of resistance caused to flow of traffic by a vehicle type when compared with standard vehicle (passenger car). Passenger Car Unit (PCU) which is a suitable measure to represent the relative impedance caused by a vehicle under heterogeneous traffic. PCU depends on vehicular speed, vehicle type, and traffic volume. In this article an attempt is made to develop PCU values for heterogeneous traffic conditions on urban roads. PCU values obtained from the study different category of vehicles is compared with the PCU values provided in IRC recommendations. It is concluded that estimated field PCU values vary with speed, land use pattern and vehicles dimensions. Traffic flow curves when plotted with optimum PCU values show close to ideal fundamental curves, this also improves considerably with the change in roadway characteristics. The curves representing fundamental traffic flow relationships among three basic variables, namely speed, density and flow have also been established. Thus a systematic approach has facilitated to understand the heterogeneity in traffic flow parameters has been made through this investigation.
\end{abstract}

Key Words: heterogeneous traffic, passenger car unit, speed, traffic volume.

\section{Background}

In developed countries traffic situation is fairly homogeneous, whereas developing countries like India it differs with the above condition. Vehicular traffic on urban roads is highly heterogeneous and mostly comprises of static followed by dynamic characteristics. The operation of vehicles on these roads is complex in nature as vehicles shall occupy same lateral space of roadway without any change in physical segregation. The heterogeneity in vehicular class are broadly categorised as: buses, truck, light commercial

${ }^{2}$ Corresponding author: ramesh_a@vnrvjiet.in 
vehicle, passenger car including jeep, three wheeler and two wheeler.

Traffic characteristics such as speed, traffic volume are considered external variables and shall be used as input while planning, design and operation of traffic elements. The mixed traffic on urban road has speed ranges from 20 to $60 \mathrm{kmph}$ with viewed physical dimensions. It is also noticed that most vehicles do not follow lane discipline as they can take any position along the available roadway space. Under this conditions expressing traffic volume as number of vehicles passing a given section of road per unit time will be inappropriate. Hence traffic flow is analysed by converting the different types of vehicles into equivalent number of passenger car unit (PCU) per hour or passenger car equivalent (PCE) per hour.

PCU is also used for evaluation of Highway capacity of different road categories and shall be used for improving the sections. It is also observed that the estimated capacities based on PCU values are different for vehicle categories. Hence these PCU value may not be considered as constant and are varied with various factors associated with it like roadway traffic characteristics.

In this article an attempt is made to understand the fundamental relationships of traffic flow characteristics and estimate the PCU values for different traffic conditions. Further these PCUs are compared with guidelines as specified in Indian Road Congress (IRC) for assessment. Chandra and Sikdar (2000) suggested a mathematical equation for estimation of Passenger Car Units (PCU) for different vehicle type. The variation of PCU was explained graphically considering geometric and traffic variables. Chandra and Kumar (2003) accessed PCU values on two way highway by categorising different class of vehicles. Arasan and Koshy (2005) provided a model for simulating the traffic flow of heterogeneity. Arasan and Arkatkar (2010) estimated PCU using variables like traffic volume of different vehicle categories and estimated road capacity. Sharma et al (2011) conducted a study on undivided two - lane road on un-interrupted mixed traffic. Traffic data were plotted for speed and headway and fundamental relationships were analysed for heterogeneous traffic flow. Arkatkar (2011) has explained that capacity is considered as most important variable for planning, analysis and operation of roadway systems. Radhakrishnan and Mathew (2011) proposed a methodology to develop a saturation model based on dynamic PCU values using microscopic analysis. Praveen. and Arasan (2013) concerned the application of micro - simulation technique for deriving PCU values on purely homogeneous (only cars) and heterogeneous traffic of all conditions for different categories of vehicles. Khanorkar and Ghodmare (2014) explained traffic flow on Indian highways by evaluating PCUs at different highway sections around Nagpur city. It is observed that PCU increases in the area of shoulder linearly for free speed of vehicles with width. The new PCUs obtained at site were compared with IRC 64 - 1990 were quite different. Arkatkar et al (2016) studied heterogeneous traffic conditions on expressway and estimated the capacity using the micro - simulation model. Mankar and Khode (2016) analysed the capacity for urban roads in heterogeneous 
traffic conditions using Greenshield model and compared with micro - simulation techniques.

Very few studies were conducted for assessment for PCU's and traffic flow characteristics on urban highway having mixed traffic conditions. An attempt is made to understand the PCU values for heterogeneity of vehicle classification.

\section{Field Data Collection}

Traffic Data was collected at mid - block section on urban highway at selected four study locations namely Bachupally, Badhurpally, Kompally and Jeedimetla of Hyderabad city. These sections were chosen to meet the requirement of land use pattern. The study section was considered as $30 \mathrm{~m}$ at each mid-block location and is shown in Fig. 1.

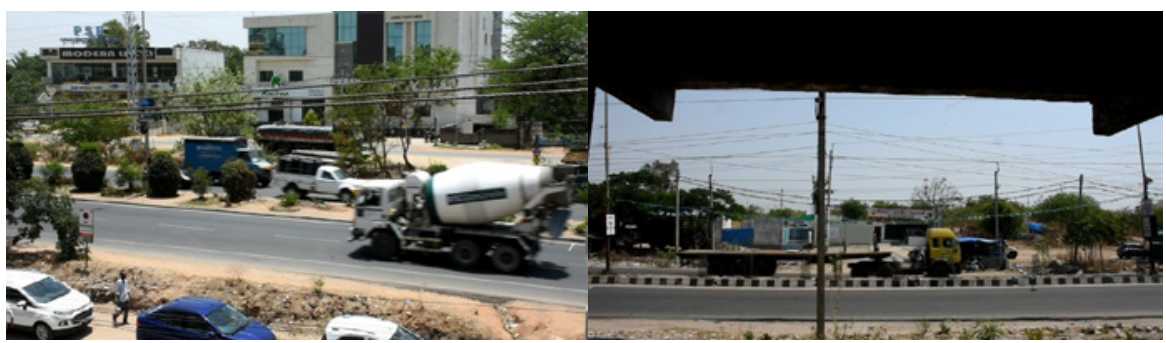

(a) Jeedimetla

(b) Bachupally

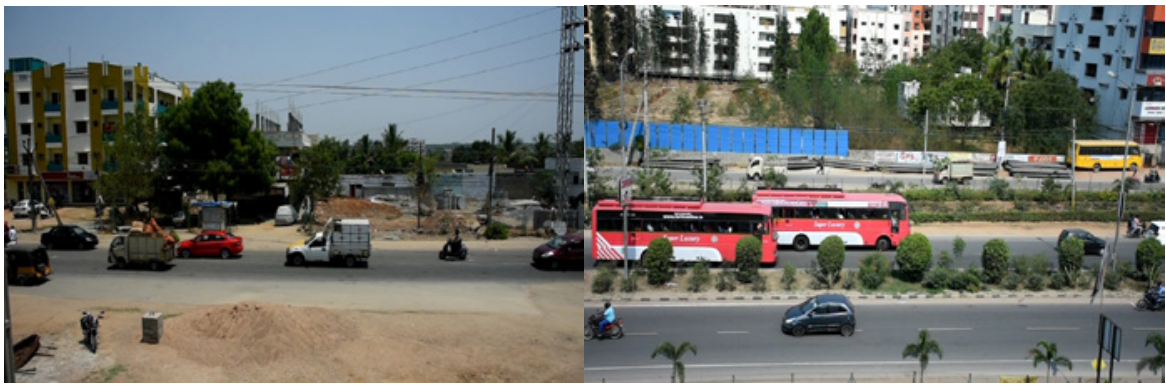

(c) Bahadurpally

(d) Kompally

Fig. 1.

Mid - Block Location Considered for Study

\subsection{Data Extraction}

The traffic data was collected by using video graphic survey and extracted using avidemux for arriving precise video's timing. It was then fragmented into frames for estimation of traffic characteristics. The vehicular dimensions are presented in Table1. 
Table 1

Physical Dimensions of Vehicles

\begin{tabular}{|c|c|c|c|}
\hline Vehicle Categories & Length $(\mathbf{m})$ & Breadth $(\mathbf{m})$ & Total Area $\left(\mathbf{m}^{\mathbf{2}}\right)$ \\
\hline Buses & 10.3 & 2.5 & 25.8 \\
\hline Trucks & 7.2 & 2.5 & 18.0 \\
\hline MAV & 11.4 & 2.5 & 28.5 \\
\hline LCV & 5 & 1.9 & 9.5 \\
\hline Passenger Car & 4 & 1.6 & 6.4 \\
\hline 3 wheeler & 2.6 & 1.4 & 3.6 \\
\hline 2 wheeler & 1.8 & 0.6 & 1.1 \\
\hline
\end{tabular}

Source: Arasan and Koshy (2005)

\section{Methods and Discussions}

The dynamic traffic characteristics was extracted which includes speed distribution, vehicle type and vehicle dimensions.

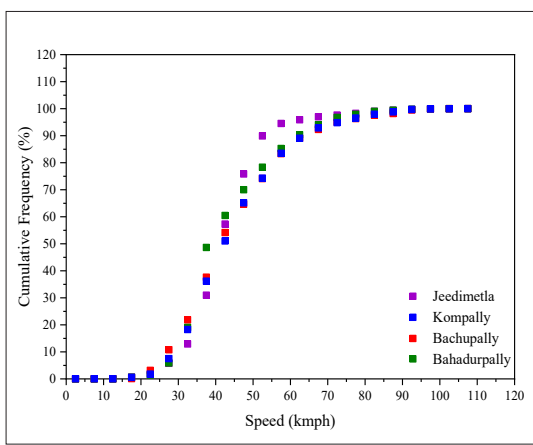

Fig. 2.

Percentage Frequency Curve at Study Locations

From Fig. 2 it is observed that average speed are baised on landuse pattern and ranges from $40-50 \mathrm{kmph}$ at all study locations. This traffic data shall be used to expedite traffic characteristics and is discussed in below section.

\subsection{Speed Distribution}

Mean speed of different vehicle classes were determined and used as variable for estimation of PCU factor. Percentage cumulative frequency curve were plotted to understand the distribution pattern and original speeds which were depicted in Fig. 2.

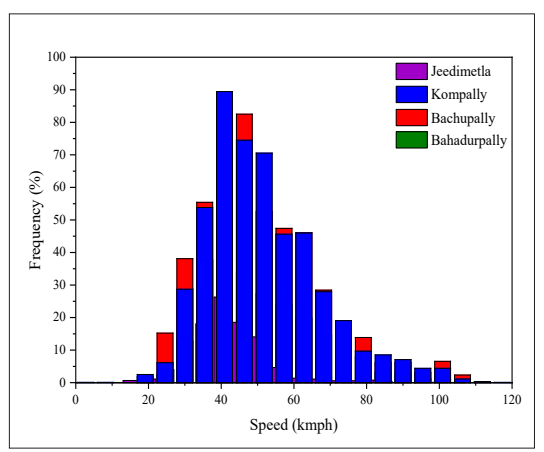

\subsection{Greenberg's Model}

This model explains the relationship between the speed and density and is logarithmic as provided in Eq. (1).

$v=v_{0} * \ln \frac{k j}{k}$ 
Where: $\mathrm{v}_{\mathrm{o}}$-optimum velocity, $\mathrm{k}_{\mathrm{j}}$-jam density

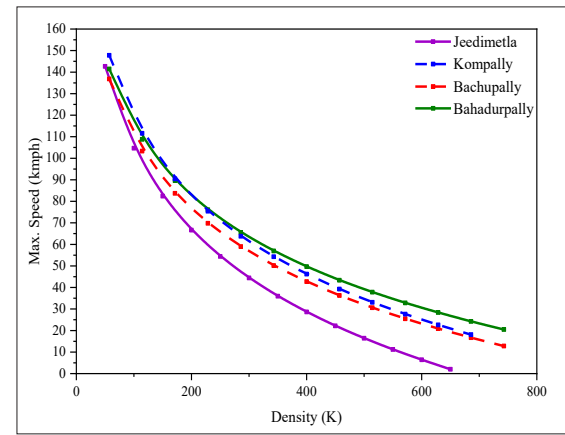

Fig. 3.

Greenberg's Speed Density Relation for Study Locations

Speed and density data collected at study locations were used in the above greenberg's model. It was observed that this model demonstrates the inability in predicting speeds at lower density as density tends to zero and speed tends to infinity and is depicted in Fig. 3.

\subsection{Fundamental Traffic Flow Relationships}

The traffic flow fundamental relationships are empirical in nature are determined from three basic variables as speed, density and flow. The field traffic data collected were used for achieve all the three primary relationships using Greenshield's model.

\subsubsection{Greenshield's Model}

This model represents the behavioural change of traffic flow parameters with speed and density as expressed in Eq. (2)

$q=k * v$

Where: $q$-flow (veh/h), $k$-density (veh/km), $v$-speed $(\mathrm{km} / \mathrm{h})$
Boundary conditions at jam density $\left(k_{j}\right)$; free flow speed $\left(v_{f}\right)$ and maximum flow, the speed - flow relationship derived from Greenshield's model are presented in Eq. (3) and Eq. (4).

Mean speed $(v): v=v_{f}-\left(\frac{v_{f}}{k_{j}}\right) * k$

flow $(q): q=v_{f} * k-\left(\frac{v_{f}}{k_{j}}\right) * k^{2}$

\subsubsection{Speed, Flow, Density Relationships}

Theoretical diagrams of traffic flow such as speed $(v)$, flow $(q)$ and density $(k)$ were determined using Greenshield's model. The field density was arrived from flow and speed data and noticed that the relationship of speed and density was obeying linearity. Flow and density was demonstrates as a parabolic curve wherein flow was directly proportional to density. As density tends to zero the flow is also observed to be zero, since there are no vehicles on the road. With increase in vehicular volume there was very less or no lateral movement of vehicles along 
the section, thus it tends to jam density and at this condition the flow is zero. The flow is observed to be maximum between zero density and jam density.

The trend observed for speed and flow was parabolic pattern. It was noticed that the flow is zero when there were no vehicles or too many vehicles (maximum flow) during this condition the vehicles cannot move and speed will vary between zero and maximum flow.

Peak Hour Factor (PHF) which is an important parameter in capacity estimation was also computed in the study. A peak 15 - min volume interval of flow was used to calculate the peak hour factor (PHF) and is expressed mathematically in Eq. (5).

PHF $=\frac{\text { hourly voulme }}{\text { peak flow rate (within hour) }}$

For the consideration of peak 15 - min periods the PHF is computed as Eq. (6):

$P H F=\frac{v_{a v}^{60}}{v_{a v}^{15} * 4}$

Where: $v_{a v}^{60}$-average volume during the peak 60 - minute period, $v_{a v}^{15} * 4$-four times of an average volume during the peak 15 - minute period

The PHF values varies with time and location and shall be used to convert the peak hour volume to that of peak rate as expressed in Eq. (7):

$P H F=\frac{v_{a v}^{60}}{v_{a v}^{15} * 4}$

Where: $v$-flow rate of a 15 - min period (veh/ hh), v-peak hour volume (veh/h)

Fig. 4 depicts the traffic flow fundamental relation for 15 minute of interval.

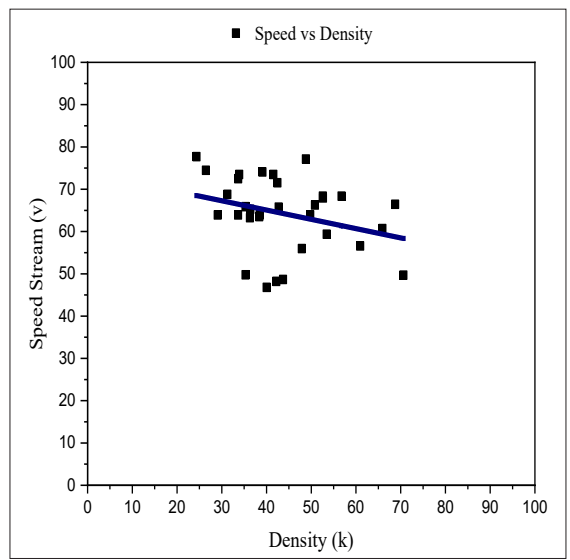

(a) Speed - Density

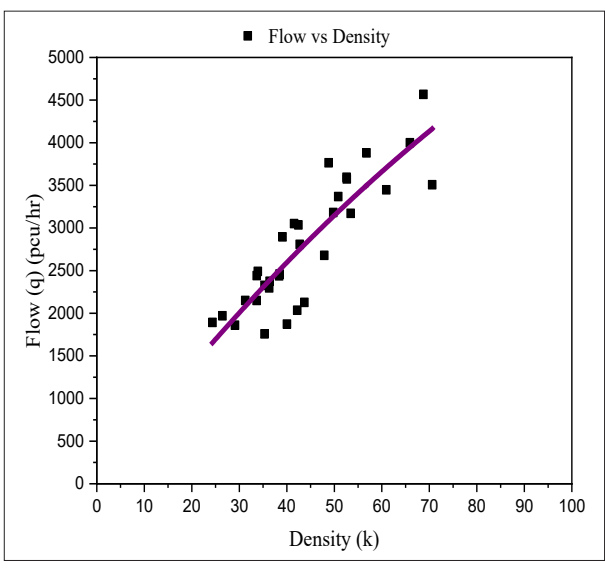

(b) Flow - Density 


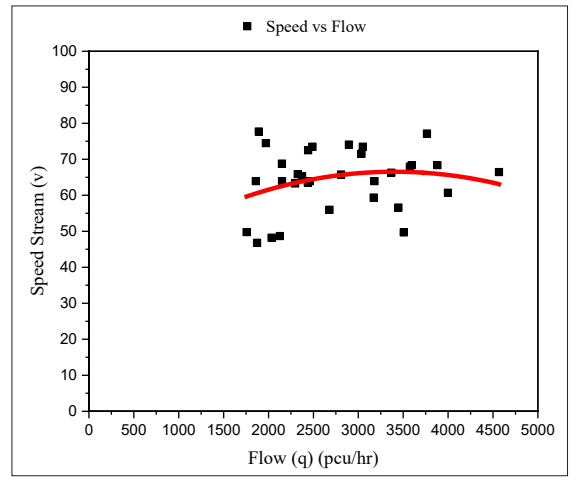

(c) Speed - Flow

Fig. 4.

Traffic Flow Relationships of at all Study Locations for Feild Data (15 Min. Interval)

Greenshield's method was used to examine how well the data was approximated to obtain a linear model having an $\mathrm{R}^{2}$ of 0.901 .

The flow - density and speed - flow were examined with Greenshield model and was following a quadratic model with parabolic profile and these models have an $R^{2}$ value of $0.759 \& 0.675$.

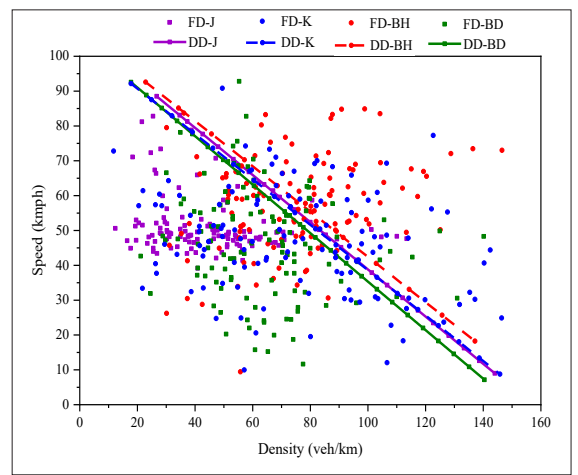

All these models demonstrate a decent fit for field observed data which are quadratic in relation.

The established of speed - flow models relates that the average speed of vehicles decreases gradually with an increase in the flow.

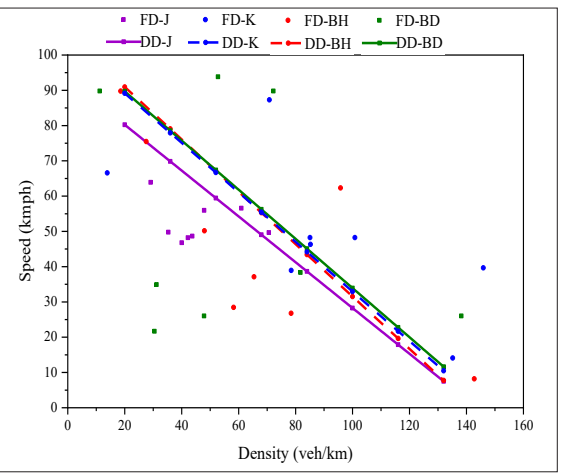



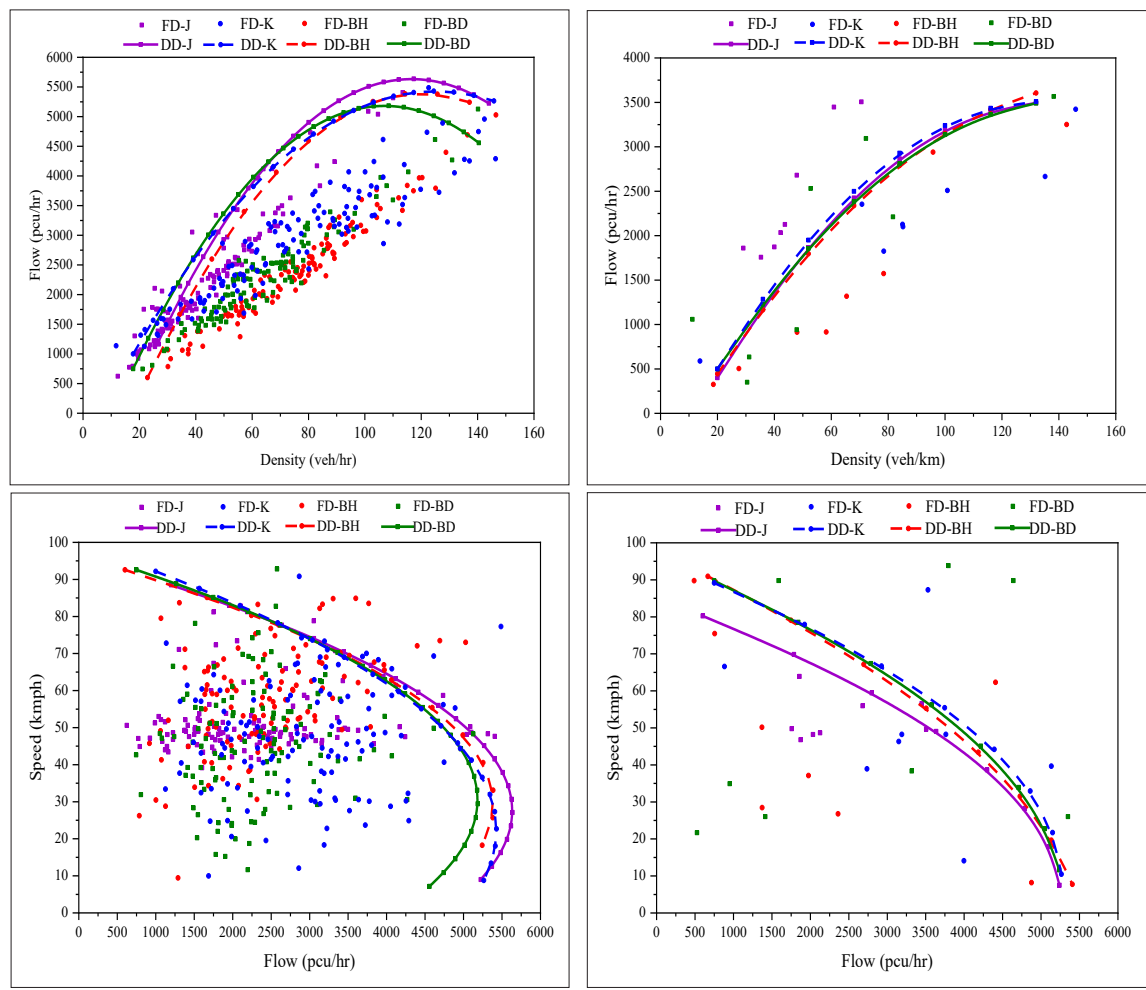

Fig. 5.

Traffic Flow Relationships using IRC PCU Values for 1 and 15 Min. Interval at all Study Locations (FD: Field Data, DD: Derived Data, J:Jeedimetla, K: Kompally, BH: Bachupally, BD: Bahadurpally)

From Fig. 5 the above theoretical diagrams and field traffic flow data it is observed that the fundamental traffic flow characteristics obeys linear relationship for speed - density; parabolic curve for flow - density and speed - flow as outlined in HCM 2000.

\subsection{Estimation of Equivalent Values (PCU)}

Passenger Car Unit (PCU) which is considered as metric to assess the traffic- flow rate. This shall be used to measure of the impact of transport mode on traffic variables as outlined in IRC SP 41.

The flow rate and peak hour volume was computed from peak hour factor using field data for 1 minute and 15 minutes interval at all study locations.

Table 2 summarizes the PHF for all study locations at different time interval. 
Table 2

Peak hour Factor at Study Locations Computed Usung IRC PCU Values

\begin{tabular}{|l|c|c|c|c|c|c|}
\hline \multicolumn{7}{|c|}{ PHF for IRC PCU values } \\
\hline \multirow{2}{*}{ Parameters } & \multicolumn{3}{|c|}{1 min. Interval } & \multicolumn{2}{c|}{15 min. Interval } \\
\cline { 2 - 8 } & $\begin{array}{c}\text { Peak hr. } \\
\text { volume }\end{array}$ & PHF & Flow rate & $\begin{array}{c}\text { Peak hr. } \\
\text { volume }\end{array}$ & PHF & Flow rate \\
\hline Jeedimetla & 2244 & 0.42 & 5406 & 2339 & 0.70 & 3320 \\
\hline Bachupally & 2699 & 0.54 & 5028 & 2730 & 0.86 & 3172 \\
\hline Bahadurpally & 2671 & 0.45 & 5982 & 2705 & 0.85 & 3181 \\
\hline Kompally & 3684 & 0.58 & 6402 & 3381 & 0.80 & 4209 \\
\hline
\end{tabular}

It was observed on urban highways that the traffic conditions were more diverse in nature, and driver do not follow lane discipline. The effect of land use on the PCU factors was not established based upon vehicle dimensions and composition as per different land use. IRC SP 41 does not provide PCU values based on the above condition. Hence the PCU values were estimated based on different land use pattern, vehicle speed and vehicular dimensions as summarized in Table 4 and the corresponding PHF was computed from field estimated PCU values at $1 \mathrm{~min}$. and $15 \mathrm{~min}$ intervals as shown in Table 3.

\section{Table 3}

Peak Hour Factor at Study Locations Computed using Field Estimated PCU Values

\begin{tabular}{|c|c|c|c|c|c|c|}
\hline \multicolumn{7}{|c|}{ PHF for estimated PCU values } \\
\hline Parameters & \multicolumn{3}{|c|}{1 min. interval } & \multicolumn{3}{|c|}{15 min. Interval } \\
\hline Locations & $\begin{array}{c}\text { Peak hr. } \\
\text { volume }\end{array}$ & PHF & Flow rate & $\begin{array}{c}\text { Peak hr. } \\
\text { volume }\end{array}$ & PHF & Flow rate \\
\hline Jeedimetla & 1894 & 0.39 & 4806 & 2001 & 0.71 & 2832 \\
\hline Bachupally & 2572 & 0.57 & 4548 & 2603 & 0.83 & 3108 \\
\hline Bahadurpally & 2579 & 0.47 & 5550 & 2599 & 0.85 & 3049 \\
\hline Kompally & 3386 & 0.58 & 5856 & 3130 & 0.86 & 3636 \\
\hline
\end{tabular}

The PCU were estimated by considering the proportionality relationship with speed and

$$
P C U=\frac{V c / V i}{A c / A i}
$$
area of occupancy with reference category as a standard area of vehicle (passenger car). The PCU of vehicle type were computed using Eq. (8) Chandra and Kumar (2003):

Where, Vc-speed of car $(\mathrm{km} / \mathrm{h})$, Vi-speed of $\mathrm{i}^{\text {th }}$ type of vehicle $(\mathrm{km} / \mathrm{h})$, A static area of a car $\left(\mathrm{m}^{2}\right)$, Ai-static area of $\mathrm{i}^{\text {th }}$ type of car $\left(\mathrm{m}^{2}\right)$.

\section{Table 4}

Filed Estimated PCU Values at Study Locations

\begin{tabular}{|l|c|c|c|c|}
\hline \multicolumn{1}{|c|}{ Vehicle type } & Jeedimetla & Bachupally & Bahadurpally & Kompally \\
\hline Buses & 4.6 & 4.9 & 5.8 & 5.6 \\
\hline Trucks & 3.2 & 3.6 & 4.2 & 3.8 \\
\hline MAV & 5.4 & 5.9 & 7.1 & 6.1 \\
\hline LCV & 1.9 & 2.3 & 1.9 & 1.8 \\
\hline Passenger Car & 1 & 1 & 1 & 1 \\
\hline 3 - Wheeler & 0.8 & 0.7 & 0.7 & 0.8 \\
\hline 2 - Wheeler & 0.4 & 0.45 & 0.46 & 0.4 \\
\hline
\end{tabular}


From Table 4 it is observed that the PCU value for a vehicle type varies with vehicular speed and corresponding compositional area. The estimated PCU values differ when compared with the IRC - recommended values because of land use pattern, mix proportion, speed and

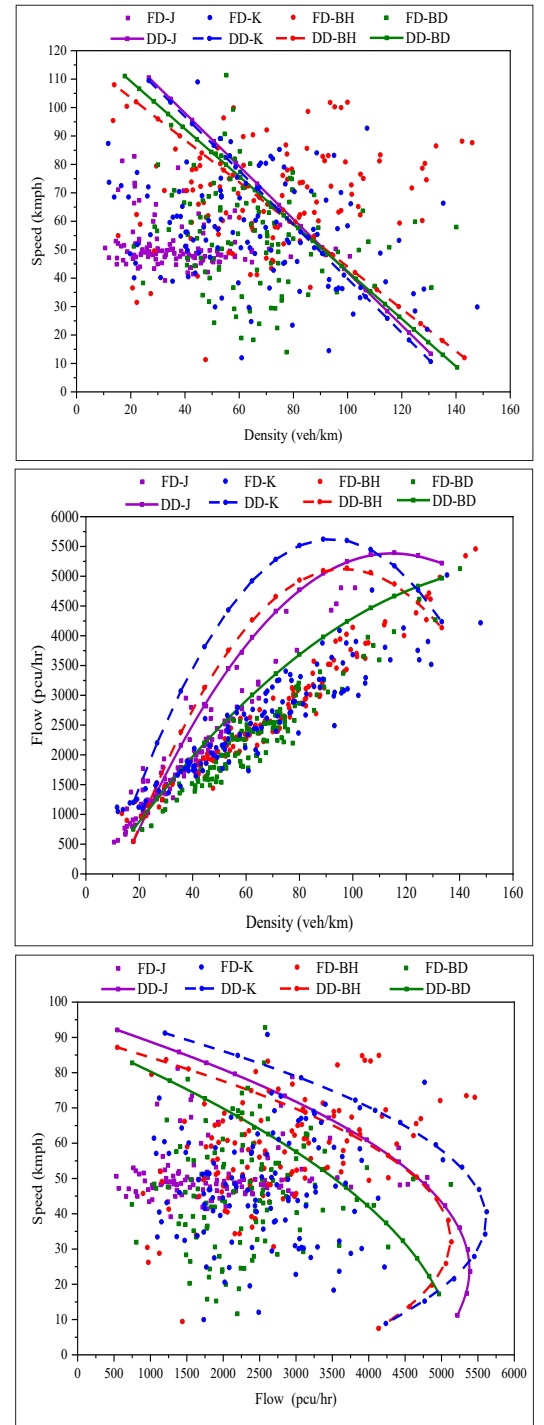

area occupancy of different vehicles in the traffic stream.

Fig. 6 provides plots for fundamental traffic flow relationships at $1 \mathrm{~min}$. and $15 \mathrm{~min}$. interval which are computed from field estimated PCU values.
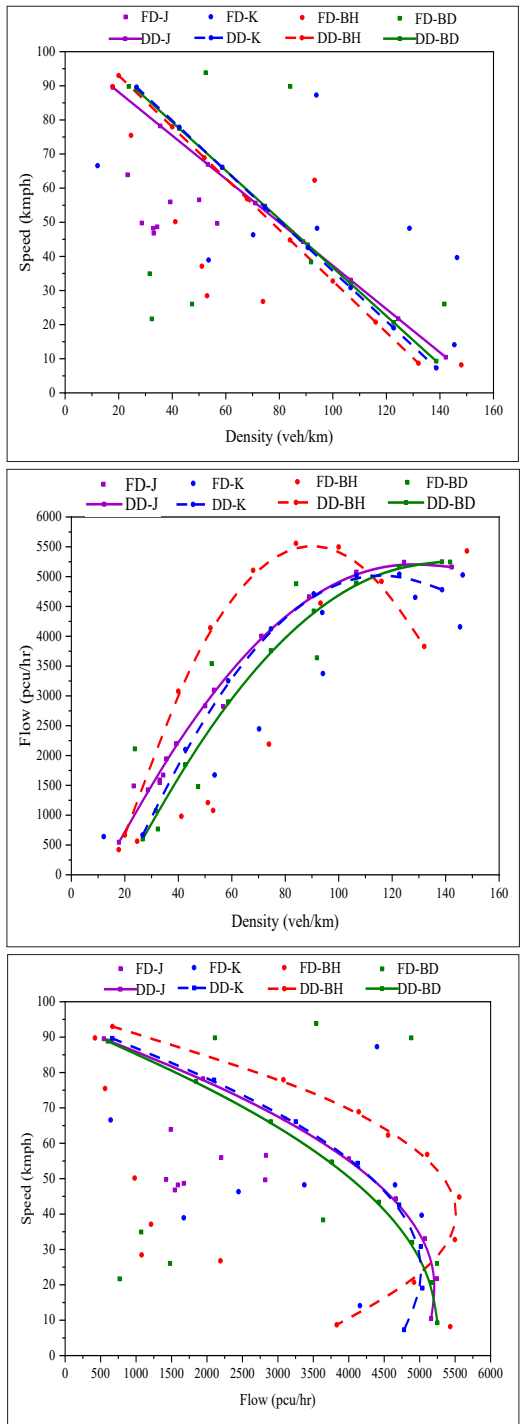

Fig. 6.

Traffic Flow Relationships using Field Estimated PCU Values for 1 and 15 min. Interval at all Study Locations 
It is observed from Fig. 6 that the field traffic flow curves are close to ideal fundamental curves. This is evident that the optimum PCUs will be successful in bringing the mixed traffic stream reasonably close to the stream of passenger cars.

\section{Summary and Findings}

In this study, the behaviour of heterogeneous traffic flow at mid - block section is analysed. Fundemental traffic flow relationships were arrived from Greenshield's Model. The filed data was used to estimate optiumum passenger car unit so as to understand the varitation with traffic characterstics:

- Filed data reveals that the relation between the speed and density was logarithmic in nature and as speed tends to infinte as desnity tends to zero;

- IRC recommended PCU values were used to compute the traffic chracterstics. Greenshield's Model was used to develop the fundematal curves;

- Opitimum PCU values were computed using traffic speed and vechular dimensions as varibles. Traffic flow curves when plotted with optimum PCU values show close to ideal fundematal curves.

\section{References}

Arasan, V.T.; Arkatkar, S.S. 2010. Microsimulation study of effect of volume and road width on PCU of vehicles under heterogeneous traffic, Journal of Transportation Engineering 136(12): 1110-1119.

Arasan, V.T.; Koshy, R.Z. 2005. Methodology for Modelling Highly Heterogeneous Traffic Flow, Journal of Transportation Engineering 131(7): 544-551.
Arkatkar, S.; Velmurugan, S.; Puvvala, R.; Ponnu, B.; Narula, S. 2016. Methodology for simulating heterogeneous traffic on expressways in developing countries: a case study in India, Transportation Letters 8(2): 61-76.

Arkatkar, S.S. 2011. Effect of intercity road geometry on capacity under heterogeneous traffic conditions using microscopic simulation technique, International Journal of Earth Sciences and Engineering 4(6): 375-380.

Chandra, S.; Kumar, U. 2003. Effect of lane width on capacity under mixed traffic conditions in India, Journal of transportation engineering 129(2): 155-160.

Chandra, S.; Sikdar, P.K. 2000. Factors affecting PCU in mixed traffic situations on urban roads, Road and transport research 9(3): 40-50.

Khanorkar, A.R.; Ghodmare, S.D. 2014. Development of PCU Value of Vehicle under mix Nature Traffic Condition in Cities on Congested Highways, International Journal of Engineering and Computer Science 3(5): 6109-6113.

Mankar, P.U.; Khode, B.V. 2016. Capacity Estimation of Urban roads under Mixed Traffic Condition, International Research Journal of Engineering and Technology 3(4): 27502755.

Praveen, P.S.; Arasan, V.T. 2013. Influence of Traffic Mix on PCU Value of Vehicles under Heterogeneous Traffic Conditions, International Journal for Traffic \& Transport Engineering 3(3): 302-330.

Radhakrishnan, P.; Mathew, T.V.; 2011. Passenger car units and saturation flow models for highly heterogeneous traffic at urban signalised intersections, Transportmetrica 7(2): 141-162.

Sharma, N.; Arkatkar, S.S.; Sarkar, A.K. 2011. Study on heterogeneous traffic flow characteristics of a two-lane road, Transport 26(2): 185-196. 